Secondhand effects due to alcohol among university students experienced at least once in the four weeks before being asked. Values are numbers (incidence; 95\% confidence interval)

\begin{tabular}{|c|c|c|c|c|c|c|}
\hline \multirow[b]{2}{*}{ Secondhand effect } & \multicolumn{2}{|c|}{ Sex of victim } & \multicolumn{3}{|c|}{ Victim's tendency to drink heavily* } & \multirow[b]{2}{*}{$\begin{array}{c}\text { Total } \\
(\mathrm{n}=1524)\end{array}$} \\
\hline & $\begin{array}{l}\text { Women } \\
(n=881)\end{array}$ & $\begin{array}{c}\text { Men } \\
(n=643)\end{array}$ & $\begin{array}{c}\text { Never } \\
(\mathrm{n}=253)\end{array}$ & $\begin{array}{l}\text { Monthly or less } \\
\quad(n=602)\end{array}$ & $\begin{array}{l}\text { Weekly or more } \\
\quad(n=669)\end{array}$ & \\
\hline Insulted or humiliated & $294(33 ; 30$ to 37$)$ & $221(34 ; 31$ to 38$)$ & $70(28 ; 22$ to 34$)$ & $175(29 ; 25$ to 33$)$ & $270(40 ; 37$ to 44$)$ & $515(34 ; 31$ to 36$)$ \\
\hline Serious argument or quarrel & $148(17 ; 14$ to 19$)$ & $136(21 ; 18$ to 25$)$ & $14(6 ; 3$ to 9$)$ & $81(13 ; 11$ to 16$)$ & $189(28 ; 25$ to 32$)$ & $284(19 ; 17$ to 21$)$ \\
\hline Pushed, hit, or otherwise assaulted & $118(13 ; 11$ to 16$)$ & $114(18 ; 15$ to 21$)$ & $21(8 ; 5$ to 12$)$ & $63(10 ; 8$ to 13$)$ & $148(22 ; 19$ to 25$)$ & $232(15 ; 13$ to 17$)$ \\
\hline Property damaged & $174(20 ; 17$ to 23$)$ & $130(20 ; 17$ to 24$)$ & $43(17 ; 13$ to 22$)$ & $110(18 ; 15$ to 22$)$ & $151(23 ; 19$ to 26$)$ & $304(20 ; 18$ to 22$)$ \\
\hline Had to take care of a drunk student & $370(42 ; 39$ to 45$)$ & $239(37 ; 33$ to 41$)$ & $45(18 ; 13$ to 23$)$ & $227(38 ; 34$ to 42$)$ & $337(50 ; 47$ to 54$)$ & $609(40 ; 37$ to 42$)$ \\
\hline Found vomit in the halls or bathroom & $201(23 ; 20$ to 26$)$ & $173(27 ; 24$ to 31$)$ & $41(16 ; 12$ to 21$)$ & $107(18 ; 15$ to 21$)$ & $226(34 ; 30$ to 38$)$ & $374(25 ; 22$ to 27$)$ \\
\hline Studying or sleep interrupted & $571(65 ; 62$ to 68$)$ & $347(54 ; 50$ to 58$)$ & $135(53 ; 47$ to 60$)$ & $323(54 ; 50$ to 58$)$ & $460(69 ; 65$ to 72$)$ & $918(60 ; 58$ to 63$)$ \\
\hline Unwanted sexual advance & $279(32 ; 29$ to 35$)$ & $151(23 ; 20$ to 27$)$ & $24(9 ; 6$ to 14$)$ & $146(24 ; 21$ to 28$)$ & $260(39 ; 35$ to 43$)$ & $430(28 ; 26$ to 31$)$ \\
\hline Sexual assault or date rape & $8(1 ; 0$ to 2$)$ & $3(0 ; 0$ to 1$)$ & $0(0 ; 0$ to 1$)$ & $3(0 ; 0$ to 1$)$ & $8(1 ; 1$ to 2$)$ & $11(1 ; 0$ to 1$)$ \\
\hline Different crime on campus & $11(1 ; 1$ to 2$)$ & $13(2 ; 1$ to 3$)$ & $4(2 ; 0$ to 4$)$ & 5 (1; 0 to 2$)$ & $15(2 ; 1$ to 4$)$ & $24(2 ; 1$ to 2$)$ \\
\hline Different crime off campus & $26(3 ; 2$ to 4$)$ & $25(4 ; 3$ to 6$)$ & $5(2 ; 1$ to 5$)$ & $20(3 ; 2$ to 5$)$ & $26(4 ; 3$ to 6$)$ & 51 (3; 3 to 4$)$ \\
\hline Any & $752(85 ; 83$ to 88$)$ & $524(81 ; 78$ to 84$)$ & $182(72 ; 66$ to 77$)$ & $476(79 ; 76$ to 82$)$ & 618 (92; 90 to 94$)$ & $1276(84 ; 82$ to 86$)$ \\
\hline
\end{tabular}

${ }^{*}$ Six or more drinks (60 $\mathrm{g}$ ethanol) on one occasion.

preceding our survey, and one fifth of students had their property damaged. ${ }^{1}$ Even non-heavy drinkers experienced several effects, some serious.

Strengths of this study include the random sampling, the high response rate, and using a computerised questionnaire, a method known to increase reporting of high risk behaviour. ${ }^{5}$ Limitations include imprecision-for example, the seriousness of "crimes" is unspecified-reliance on respondents to attribute responsibility for the effect, and our focus on students alone.

The needs of the many non-drinkers and moderate drinkers who are harmed by heavy drinkers should be considered when devising local and national alcohol policies. Universities and colleges should tackle environmental risk factors for hazardous drinking-for example, the availability and promotion of alcohol on and around campus-and should provide screening and intervention services for students with patterns of hazardous drinking.

We thank Dorothy Begg and Margaret Geddis for comments on an earlier version of this paper.
Contributors: JDL got funding for the study, designed the study, analysed the data, and wrote the paper. KK got funding for the study, designed the study, managed and analysed the data, and wrote the paper. SCRS managed and analysed the data and reviewed the paper. KK is guarantor.

Funding: Health Research Council of New Zealand and Alcohol Advisory Council of New Zealand.

Competing interests: None declared.

Ethical approval: University of Otago ethics committee.

1 Wechsler H, Lee JE, Kuo M, Seibring M, Nelson TF, Lee H. Trends in college binge drinking during a period of increased prevention efforts: findings from four Harvard School of Public Health college alcohol study ings from four Harvard School of Public Health collegr

2 Kypri K, Langley JD, McGee R, Saunders JB, Williams S. High prevalence, persistent hazardous drinking in New Zealand tertiary students. Alcoho Alcohol 2002;37:457-64.

3 Kypri K, Gallagher SJ. Incentives to increase participation in an internet survey of alcohol use: a controlled experiment. Alcohol Alcohol 2003;38:437-41.

4 Saunders JB, Aasland OG, Babor TF, de la Fuente JR, Grant M. Development of the alcohol use disorders identification test (AUDIT): WHO collaborative project on early detection of persons with harmful alcohol consumption II. Addiction 1993;88:791-804.

5 Turner CF, Ku L, Rogers SM, Lindberg LD, Pleck JH, Sonenstein FI Adolescent sexual behaviour, drug use, and violence: increased reporting with computer survey technology. Science 1998;280:867-73.

(Accepted 15 July 2003)
St Michael's

Hospital, University of Toronto, 30 Bond Street, Toronto, ON Canada M5B 1W8 Simone N Vigod medical student

Department of Medicine,

St Michael's

Hospital, University

of Toronto

Chaim M Bell

assistant professor

continued over

BMJ 2003;327:1024-5
Respect for the confidentiality of patients' information is a basic principle of ethical and effective medical practice. It ensures individual patients' privacy, and, more broadly, it upholds public perception of the quality of the healthcare system and its professionals. Observational studies have shown that breaches of patients' confidentiality by healthcare professionals occurred in 3\%-7\% of lift rides in hospitals. ${ }^{12}$

Even though most healthcare professionals know the limits of confidentiality well, they have trouble applying them to their behaviour, particularly in hospital lifts where discussions of patients' information may be overheard. ${ }^{3}$ To decrease the risk of compromising patients' confidentiality in public spaces in hospitals, we investigated the number and nature of comments that compromise patient confidentiality in hospital lifts and the reactions of colleagues who witnessed these comments.

\section{Participants, methods, and results}

We instructed medical students in the information privacy policy of St Michael's Hospital, a tertiary care centre in Toronto, Canada. They recorded the date, time, duration, and location of every journey they took in a public lift at St Michael's Hospital during regular hours for two weeks in November 2002. 
These observers excluded journeys where only their own healthcare team was present because no healthcare professional, patient, or visitor was present to witness a compromise of patient confidentiality. Observers, who were identifiable as medical students, recorded all breaches of patients' confidentiality by hospital staff and any reactions by witnesses to these comments.

Hospital caregivers made 18 comments deemed to compromise a patient's confidentiality on 13 out of 113 lift journeys (observers overheard multiple comments on some journeys). Doctors made the most comments (11), then allied health professionals (6), and then nurses (1). Most comments referred to patients by their initials or reason for admission, but names were used four times.

Reactions attempting to minimise breaches of patients' confidentiality happened only twice. Both times medical students naive to the existence of our study politely asked that the conversation be continued in another location. The students' interventions were successful.

\section{Comment}

Patient confidentiality was compromised on more than one in ten lift journeys, strengthening the evidence that public lapses in patient confidentiality are widespread. ${ }^{12}$ Most comments disguised patient identity, which shows awareness of the need for discretion in public spaces and the motivation to uphold it. But clarification of what constitutes a breach in patient confidentiality is needed.
The small number of reactions (to less than a tenth of comments) shows that other healthcare workers in elevators are either reticent or lack awareness. The silence of witnesses may even perpetuate the problem; on several occasions, breaches in confidentiality started conversations that further compromised patients' privacy.

Breaches of a patient's confidentiality compromise ethical health care and undermine patients' confidence in caregivers. Healthcare institutions must provide effective training to minimise these breaches. We hope that providers here and in all healthcare institutions will heed the call to improve discretion for the patients who entrust us with their care.

We thank our observers, all medical students at the University of Toronto at the time we did the study: Melissa Albin, Sonia Butalia, Patrick Cervini, Jared Peck, and Gregory Silverman.

Contributors: JMAB conceived of the study. All authors designed the study, interpreted the data, and revised the paper. SNV analysed the data and drafted the paper. CMB and JMAB approved the final draft. JMAB is guarantor.

Funding: No additional funding.

Competing interests: None declared.

Ethical approval: Research ethics board, St Michael's Hospital.

1 Ubel PA, Zell MM, Miller DJ, Fischer GS, Peters-Stefani D, Arnold RM. Elevator talk: observational study of inappropriate comments in a public space. Am J Med 1995;99:190-4

2 Hasman A, Hansen NR, Lassen A, Rabol R, Holm S. [What do people talk about in Danish hospital elevators?] Ugeskr Laeger 1997;159:6819-21. (In Danish.)

3 Grady C, Jacob J, Romano C. Confidentiality: a survey in a research hospital. J Clin Ethics 1991;2:25-30, discussion 30-4.

(Accepted 5 August 2003)
Departments of Surgery and Health Policy, Management and Evaluation, St Michael's Hospital, University of Toronto

John M A Bohnen associate professor

Correspondence to: J M A Bohnen

bohnenj@

smh.toronto.on.ca

\title{
Risk of suicide and spouse's psychiatric illness or suicide: nested case-control study
}

\author{
Esben Agerbo
}

Suicides cluster in families with histories of psychiatric disorders and suicides. ${ }^{12}$ Genetic and environmental factors may play a role in the familial aggregation of suicides but are inseparable in most studies. Because married couples are usually genetically unrelated, studying them can identify environmental factors and means of protection. Your spouse dying or your spouse having a psychiatric disorder is stressful; mortality is increased in the surviving spouse. ${ }^{3}$ I investigated the association between a spouse's psychiatric illness, suicide, and other causes of death and own suicide.

\section{Participants, methods, and results}

I got data by linking population based registers using unique personal identification numbers, which are assigned to all people living in Denmark. Until 1993, suicide was defined as ICD-8 (international classification of diseases, 8th revision) codes E950-E959; after 1994, ICD-10 codes X60-X84. I matched each person aged 25 to 60 years who had committed suicide during
1982-97 to a random subsample of 20 people stratified by sex and year of birth. I only enrolled people who had been living in Denmark for the past two years. I identified all spouses and children who were living with these people on 31 December two years before the suicide. I got admission and discharge dates and diagnoses from the Danish psychiatric central register, which has monitored all facilities for inpatients since $1969 .^{12}$ I analysed the data with conditional logistic regression.

I identified 9011 suicides, 180220 controls, and 111172 spouses (table). People whose spouse had ever been admitted with a psychiatric disorder were at greater risk of committing suicide, particularly if the first admission had been recent (risk ratio 5.09; 95\% confidence interval 3.53 to 7.35). People whose spouse had died, especially by suicide $(21.69 ; 11.10$ to 42.37$)$, were also at a greater risk of committing suicide. An adjusted analysis found weaker associations, but a spouse's suicide remained indicative of own suicide $(\mathrm{P}=0.01)$.
National Centre for Register-based Research, University Research, University
of Aarhus, DK- 8000 Aarhus C, Denmark Esben Agerbo assistant professor ea@ncrr.dk

BMJ 2003;327:1025-6 